\title{
The nature of concussion: a speculative hypothesis
}

Concussion is one of the commonest forms of neurological injury seen throughout the world. Although common in sport, this condition has parallels in the types of injury suffered in motor vehicle crashes, falls, and other forms of brain trauma. ${ }^{1}$ Despite the fact that the effects of brain injuries have been recognised for at least 3000 years and the clinical state of concussion initially described over 1000 years ago, ${ }^{2}$ the understanding of the pathophysiology of these injuries remains limited. One issue that remains difficult to reconcile is the absence of consistent neuroimaging abnormalities in the face of dramatic symptoms. This may in part be because concussion is due to a functional rather than structural lesion but also that the anatomical locus may be not cortical as is often assumed.

\section{Clinical features}

The acute symptoms of concussion are described in detail in many published studies. Prospectively validated signs and symptoms include amnesia, loss of consciousness, headache, dizziness, blurred vision, attentional deficit, and nausea. ${ }^{3-7}$ The attentional deficit is often loosely described by clinicians as "confusion" or "disorientation". While these terms are often seen as sine qua non of concussion, it is more scientifically appropriate to use the correct terminology. Other recently documented clinical features of acute concussion include convulsive and motor phenomena. ${ }^{8}$

Most of these symptoms are protean and non-specific in terms of cerebral localisation. The only symptom complex that is more likely to represent cortical or subcortical dysfunction is memory disturbance. Traditional neurological thinking would suggest that the anatomical locus for such symptoms should be in the temporal lobes or orbitotemporal region.

\section{Biomechanical theories of concussion}

In 1974, Ommaya et al developed the centripetal theory of cerebral "concussion". This theory invokes the geometric structural and material properties of the cranium and its contents. In this theory, the diffuse effects of the rotational component of inertial loading are produced by a centripetal progression of strains from the outer surfaces to the core of the brain (coinciding with the midbrain and basal diencephalon). At low levels of inertial loading, injurious levels of shear strain would not extend deeper than the cortex, while strains large enough to reach the well protected mesencephalic part of the brainstem would result in loss of consciousness. ${ }^{9}{ }^{10}$

Such biomechanical concepts are based on primate research and the authors readily allow that mild brain injury may not necessarily follow these principles. ${ }^{911}$ Nevertheless based upon these concepts, concussion severity grading scales and management strategies for sporting concussion have been proposed. If the underlying theory is incorrect then it follows that most if not all the existing grading scales are brought into question. ${ }^{12}$

\section{The "centripetal theory" revisited}

The association of putative brainstem phenomena-for example, loss of consciousness, convulsive phenomena-in the setting of concussion raises some challenging conceptual issues. If this centripetal theory holds true, then in milder concussive injury, "cortical" symptoms such as memory disturbance should predominate whereas only more severe injuries should manifest mesencephalic or brainstem symptoms such as loss of consciousness or motor phenomena. The observation that brainstem signs can occur in the absence of significant "cortical" symptomatology suggests that the clinical symptomatology of concussion may be more complex than the previously held view, and that the "centripetal theory" does not hold for all cases. ${ }^{813}$

The traumatic coma of experimental cerebral "concussion" has also been associated with failure of activity in the mesencephalic reticular formation and with loss of brainstem reflex response without evidence of cortical involvement. ${ }^{10}{ }^{14}$ Several studies in different animal models of experimental concussion have also demonstrated ultrastructural and biochemical alterations in the brainstem structures. ${ }^{15} 16$

Although the symptoms of amnesia may be due to cortical dysfunction, some authors have postulated that amnestic symptoms may also be due to isolated brainstem disturbance where ascending cortical projections are disturbed in the absence of cortical or subcortical pathology. ${ }^{17} 18$ Neuroimaging studies similarly have been unsuccessful in determining either consistent evidence of structural pathology in mild head injury or evidence of a "centripetal" gradient of injury severity, which would be predicted by the Ommaya theory.

\section{Speculation on the nature of concussion}

In contrast to concussion, our clinical understanding of severe brain injury is underpinned by firm experimental data. Extrapolation of the conceptual understanding of severe injuries to mild brain injury may be inappropriate given the structural rather than functional nature of neurological dysfunction in these cases. ${ }^{19-21}$

Could there be a "brainstem concussion" as distinct from "cortical concussion"? We speculate that the nature of the clinical symptoms of concussion, the existence of motor and convulsive movements, the experimental animal evidence of brainstem signs in concussion, and the absence of neuroimaging evidence of structural brain injury would be in keeping with this hypothesis.

Similarly the constellation of symptoms known as the "post-concussive syndrome" (including vacant stare, irritability, emotional lability, impaired coordination, sleep disturbance, noise/light intolerance, lethargy, behavioural disturbance, and altered sense of taste/smell) are equally difficult to localise and may reflect a global activation or attentional deficit rather than focal injury.

From a clinical stand point, management strategies may need to be rethought. Does a "brainstem concussion" differ in severity or prognosis from a cortical concussionthat is, amnestic concussion? Is there likely to be a different outcome for the athlete who wakes up cognitively intact after a concussive loss of consciousness as compared to an athlete with prolonged amnestic symptoms? Should the management guidelines reflect such situations?

\section{Conclusion}

It is likely that the entity of concussion reflects a functional membrane dysfunction with the bulk of the anatomical focus in the brainstem. The presence of memory disturbance however, is likely to reflect at least some cortical pathology, although brainstem mechanisms do exist to account for such phenomena. This hypothesis would thus explain the absence of structural cortical pathology and the protean nature of the clinical symptoms more specifically 
than the existing centripetal hypothesis of Ommaya. The simplistic view of head injury being a linear spectrum from mild to severe with neuropathological accompaniments explaining clinical symptoms does not accord with clinical practice. This in turn has important implications for our conceptual understanding of concussion in relation to the spectrum of head injury and the development of appropriate management strategies.

PAUL MCCRORY

Centre for Sports Medicine Research and Education and the Brain,

Research Institute University of Melbourne, Parkville, Victoria,

Australia 3052

pmccrory@compuserve.com

1 Jennett B. Epidemiology of head injury. 7 Neurol Neurosurg Psychiatry 1996;60:362-9.

2 Rhazes A. Opera medica varia. Venice: Bonetus Locctellus, 1497.

3 Levin HS, Mattis S, Ruff R, et al. Neurobehavioural outcome following Levin HS, Mattis S, Ruff R, et al. Neurobehavioural outcome follow
minor head injury: a three centre study. F Neurosurg 1987;66:234-43.

4 Maddocks D, Dicker G. An objective measure of recovery from concussion Maddocks D, Dicker G. An objective measure of recovery from
in Australian rules footballers. Sport Health 1989;7(suppl): $6-7$.

5 Maddocks DL, Dicker GD, Saling MM. The assessment of orientation folMaddocks DL, Dicker GD, Saling MM. The assessment of or
lowing concussion in athletes. Clin $\mathcal{F}$ Sport Med 1995;5:32-5.

6 McCrea M, Kelly J, Randolph C, et al. Standardised assessment of concussion (SAC): on site mental status evaluation of the athlete. F Head Trauma Rehab 1998;13:27-36.

7 McCrory PR. Were you knocked out? A team physician's approach to initial concussion management. Med Sci Sports Exerc 1997;29(7 suppl):S207-12.
8 McCrory PR, Berkovic SF. Video analysis of acute motor and convulsive manifestations in sport-related concussion. Neurology 2000;54:1488-91.

9 Ommaya A. Head injury mechanisms and the concept of preventative management: a review and critical synthesis. $\mathcal{F}$ Neurotrauma 1995;12:52746.

10 Ommaya AK, Gennarelli TA. Cerebral concussion and traumatic unconsciousness. Correlation of experimental and clinical observations of blunt head injuries. Brain 1974;97:633-54

11 Gennarelli TA. The spectrum of traumatic axonal injury. Neuropathol Appl Neurobiol 1996;22:509-13.

$12 \mathrm{McCrory}$ P. You can run but you can't hide: the role of concussion severity grading scales in sport. Br $\mathcal{F}$ Sports Med 1999;33:297-8.

13 McCrory PR, Ariens T, Berkovic SF. The nature and duration of acute concussive symptoms in Australian football. Clin F Sport Med 2000;10:235-8.

14 Denny-Brown D, Russell WR. Experimental cerebral concussion. Brain 1941;64:93-163.

15 Brown W. Experimental concussion. Ultrastructural and biochemical correlates. Am f Pathol 1972;67:41-68.

16 Jane JA, Steward O, Gennarelli T. Axonal degeneration induced by experimental noninvasive minor head injury. $\mathcal{F}$ Neurosurg 1985;62:96-100.

17 Goldberg E, Antin SP, Bilder RM, Jr, et al. Retrograde amnesia: possible role of mesencephalic reticular activation in long-term memory. Science 1981;213:1392-4.

18 Goldberg E, Hughes J, Matis M, et al. Isolated retrograde amnesia: different aetiologies, same mechanisms? Cortex 1982;18:459-62.

19 Hovda D, Lee S, Smith M, et al. The neurochemical and metabolic cascade following brain injury: moving from animal models to man. $\mathcal{F}$ Neurotrauma 1995;12:903-6.

20 Povlishock JT, Pettus EH. Traumatically induced axonal damage: evidence for enduring changes in axolemmal permeability with associated cytoskeletal change. Acta Neurochir Suppl 1996;66:81-6.

21 Shetter A, Demakis J. The pathophysiology of concussion: a review. Adv Neurol 1979;22:5-14.

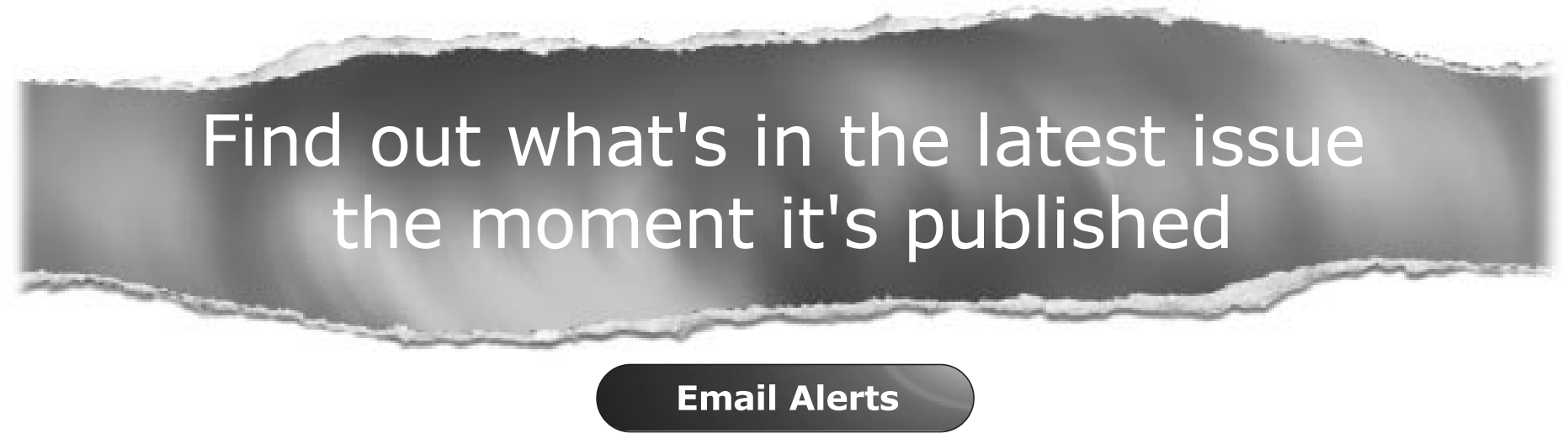

Sign up to receive the table of contents by email every month. You can select from three alerts: Table of Contents (full), TOC Awareness (notice only); British Journal of Sports Medicine related announcements.

www.bjsportmed.com 


\section{Expression of concern about content of which Dr Paul McCrory is a single author}

This paper is authored by Dr Paul McCrory. During 2021 and 2022 there was an investigation by BJSM and BMJ which found that some of his work was the product of publication misconduct. Such misconduct includes plagiarism, duplicate publication, misquotation and misrepresentation in publications in respect of which he was listed as the sole author. ${ }^{1}$ We are placing a notice to readers on all content in relation to which he is identified as the sole author to alert them to the conclusions of our investigation.

(C) Author(s) (or their employer(s)) 2022. No commercial re-use. See rights and permissions. Published by BMJ.

Br J Sports Med 2022;0:1. doi:10.1136/bjsports-2022-106408eoc

D) Check for updates

\section{REFERENCE}

1 Macdonald H, Ragavooloo S, Abbasi K. Update into the investigation of former BJSM editor-in-chief Paul McCrory. Br I Sports Med 2022. 